\title{
Influences of COVID-19 on Environment
}

\author{
Hina Ayub* \\ University of Narowal, Pakistan \\ ${ }^{\star}$ Corresponding author: Hina Ayub, University of Narowal, Near Jassar Bypass Circular Road, Narowal, Pakistan; E-mail: hinarajpoot1112@gmail.com
}

Received: February 09, 2021; Accepted: February 13, 2021; Published: February 20, 2021

\begin{abstract}
This study shows positive and negative effects of coronavirus on the environment and also tests how individual mobility has affected by the spread of local diseases and homoeopathic regulations in the epidemic of coronavirus. Meanwhile, solitary confinement can affect intellectual strength and purpose of this study is to quantify the occurrence of sadness, nervousness, and sleep illnesses in the world during incarceration. I associate educated air pollution levels with unusually high atmospheric precipitation levels in different parts of the world. Electricity demand has significantly abridged because of the current COVID-19 epidemic. Administrations worldwide are being forced to cut business operations in comeback to reducing the hazard of coronavirus. This continuing condition because of coronavirus epidemic has altered the lifestyle around the world as people live at home and work at home when possible. Therefore, there is a noteworthy rise in the claim for real estate and also with this; there is a considerable reduction in trade and manufacturing things. That dire circumstance poses novel tasks to the power sector's practical and economic services, which is why many resources around the world have embarked on a disaster risk management program to address these ongoing challenges/threats. Satellite data has shown declining air pollution levels in many areas of the earth. This review purposes to examine the global COVID-19 conditions worldwide.
\end{abstract}

Keywords: COVID-19, Electricity demand, Depression, Industrial goal, Pollution

\section{Introduction}

Negotiation research spans many disciplines [1] and 2019 Coronavirus (COVID-19) become the leading cause of shortest and unintended mental and public outcomes (M.H.) Not only during each epidemic but also in the upcoming era. This outcome of segregation has assessed throughout earlier epidemics, e.g., a respiratory syndrome (SARS) outburst in the year of 2003 and Ebola in the year of 2014, showing that the influence of M.H. will be extensive, significant, and lifelong [2]. In his report [2] explained that Between the effects of isolation there are severe depressive illnesses, fatigue, tetchiness, stress, low awareness and uncertainty, impaired work routine, stress disorder, severe depression, symptoms of depressive, and sleeplessness. The existing data that could predict M.H. conclusions are contradictory [2], e.g., Stage of development, schooling, gender, and childbearing has considered both [3] and outside [4] to meet psychological problems. Besides, M.H.'s principal stresses during separation sometimes resulted in a period of separation, fear of contagion, hindrance, insufficient purchases, and insufficient evidence [2]. In China, the physical reaction during the breakdown of COVID-19 has widely studied. Findings from China reported an increase in stress during the separation by up to $37 \%$ [3] and increased anxiety by up to $35 \%$ [5].

As mentioned, the main purpose of the current study to quantify the mental impact of COVID-19 and the corresponding prevention strategies in a nationwide study that has examined an increase in depressive, anxiety, and sleep disorders around the world.

A explained above, this study aims to show the positive and negative effects of COVID-19 on the environment and evaluate how different matters have been affected by the spread of local diseases and homoeopathic regulations during the COVID-19 epidemic

\section{The Consequence of Psychological Health}

The coronavirus 2019 epidemic (COVID-19) and the international outreach programs they have developed have disrupted daily activities.

Negotiation research spans many disciplines [6]. The disease COVID-19 has led to unprecedented prevention in many cities and regions in China [7]. Further studied [8] that School habits are important ways to deal with the mental and physical health problem of young people. During the epidemic, when education is almost restricted to online system and institutions are closed, students lose balance in their lives and show the symptoms of restlessness. The infection of COVID-19 has characterized by respiratory depression, which has prompted Herculean efforts to increase respiratory equipment supply in the United States It has also reported that health care workers, whether directly or partially in contact with the health care system that provides care for people with SARS, experience significant levels of depression supported over one year after the outbreak, showing that the reaction is not just a correction problem [9]. This is unparalleled by people with limited resources and poor health. Communal loneliness measures can lead to separation of an individual in an offensive home, through trauma probable to increase during this period of commercial uncertainty and pressure [6].

\section{Atmosphere Quality}

The COVID-19 epidemic has certainly changed the issue, as, for instance, public devote extra time at home and fewer time on the road [10]. This effect has been widely studied $[11,12]$ Low mobility reduces 
nitrogen oxides, a significant fire product. A total drop in atmospheric $\mathrm{NO} 2$ in the spring of 2020 indicates this emission's result. NO2 is focused in town areas and is easily visible. In the space, satellite descriptions have provided a pure sign of declining population density in current months, encouraging observation on refining air superiority). Negotiation research spans many disciplines [13] Decreases have been severe in areas controlled by diesel automobiles, with more NOx emissions than in other petrol. At the same time, the relief of NO2 satellite imagery has led many to focus on changes in NOx discharges, which means that many factors complicate this reduction of COVID-19. It is reported [14] At the similar time, an analysis of variations in the atmosphere over the past few months, and in the coming months with the decrease (and redistribution) of COVID-19 grounded limitations, will deliver an original, complete understanding of chemicals, including secondary emissions and secondary pollution.

\section{Commercial Outcomes}

As a result of the COVID-19 epidemic, the worldwide economy has been collapsed almost overnight [15]. The worldwide economy is severely pretentious by these actions and rises redundancy and shortage. This poses threats to achieving the U.N.s goal of Sustainable Development Goals (S.D.G. s). The COVID-19 epidemic has taken its toll on the world. Whenever there is a significant shift in economic activity, it will have an impact on the environment. The epidemic faces the tourism industry with an unprecedented challenge. COVID-19 curve strategies such as public closure, public evacuation, home instructions, travel, and travel boundaries have controlled the momentary closing of many hospitality trades and meaningfully abridged businesses' necessity to continue operating that is exclaimed by [16]. All cafeterias were asked to shut down their shops during the severe condition. The restrictions imposed on travel and accommodation orders issued by the authorities have resulted in a significant reduction in hotel accommodation and revenue. To explore how government assistance can be prioritized in the tourism sector, we align [17] a security market-based approach to mimic the impact of COVID-19 on the hotel, aviation, boat, and rental industries. We see that shock is not a single event, but instead better followed as there is a changing nature.

Negotiation research spans many disciplines $[18,19]$ As per there is no cure up till now, keeping a distance is the best way to overcome the spreading of disease, and many countries set for a country with a strong closure, social restrictions, travel restrictions, unemployment, and home plan have enforced most people to stay indoors, which has affected standard professional operations and condensed demand for power on the countrywide network. Industries have moved to less manual labour or limit their efficiency. The business declined their performance; travel restrictions almost collapsed in the flight business, small companies almost stagnant, schools, universities moving to an online method, and many other parts are embracing domestic policy.

This effect has been widely studied by [20-24]. The catastrophic event has affected the country's social and economic spheres. Strict closures have halted industrial operations due to staff shortages and limited business due to travel restrictions. Although all community transportation modes are not electric, in many countries and essential parts of all transportation are electricity such as; Streetcar, train and common transportations so, limited traffic has affected the demand for electricity in the transport sector. Most governments and organizations around the world are putting forth effort and money to fight coronavirus disease. Therefore, there may be delays or reductions in funding for many research projects, such as reusable energy programs. On the other hand, this effect has been widely studied [25-27] the epidemic has created several diverse research gaps such as medical emergency management, mental health care $[28,29]$. Negotiation research spans many disciplines [30-32] economic recovery, and energy subdivision supervision to accomplish the electricity system in such critical situations, etc. Strict closures have halted industrial operations due to staff shortages and limited business due to travel restrictions. All of this has indirectly contributed to reducing pollution in the industrial sector, which positively affects the environment [33-41].

\section{Conclusion}

Coronavirus has affected humans and the environment directly or indirectly. It has affected the economy rate of every country, besides this also human health is affected badly. Due to coronavirus, only Air pollution has decreased.

\section{Acknowledgement}

I acknowledge my parents and also every author whose research I have considered in my review article.

\section{References}

1. Holmes EA, et al. (2020) Multidisciplinary research priorities for the COVID-19 pandemic: a call for mental health science action. The Lancet Psychiatry.

2. Brooks SK, Webster RK, Smith LE, Woodland L, Wessely S, et al. (2020) The psychological impact of quarantine and how to reduce it: Rapid review of the evidence. Lancet 395: 912-920.

3. Taylor MR, Agho KE, Stevens GJ, Raphael B (2008) Factors influencing psychological distress during a disease epidemic: Data from Australia's first outbreak of equine influenza. B.M.C. Public Health 8: 347. [crossref]

4. Hawryluck L, Gold WL, Robinson S, Pogorski S, Galea S, et al. (2004) SARS control and psychological effects of quarantine, Toronto, Canada. Emerg Infect Dis 10: 12061212

5. Huang Y, Zhao N (2020) Generalized anxiety disorder, depressive symptoms, and sleep quality during COVID-19 outbreak in China: A web-based cross-sectional survey. Psychiatry Res 288: 112954. [crossref]

6. Lee J (2020). Mental health effects of school closures during COVID-19. The Lancet Child \& Adolescent Health 4: 421. [crossref]

7. Gates B (2020) Responding to Covid-19: a once-in-a-century pandemic? N Engl J Med 382: 1677-1679. [crossref]

8. Boyer J (2020) COVID-19, medication-assisted treatment, and increased risk for further respiratory depression. American Journal of Psychiatry 177: 636-636. [crossref]

9. Lee AM, Wong JGWS, McAlonan GM, et al. (2007) Stress and psychological distress among SARS survivors one year after the outbreak. Can J Psychiatry 52: 233-240. [crossref]

10. Quéré L, et al. (2020) Nat Clim Chang 8: 647-653.

11. Bauwens M, et al. (2020) Geophys Res Lett 47: 2020GL087978.

12. Liu, F. et al. (2020) Science Advances 6: 2992. 
13. Weiss M, Bonnel P, Hummel R, Provenza A Manfredi U (2011) Environ Sci Technol 45: 8575-8581.

14. Le T, et al. (2020) Science 369: 702-706.

15. UNWTO (2020) UNWTO world tourism barometer. 18.

16. Bartik AW, Bertrand M, Cullen ZB, Glaeser EL, Luca M (2020) How are small businesses adjusting to COVID-19? Early evidence from a survey (No. w26989). National Bureau of Economic Research.

17. Karafiath I (1988) Using dummy variables in the event methodology. The Financial Review 23: 351-357.

18. Chintalapudi N, Battineni G, Amenta F (2020) COVID-19 virus outbreak forecasting of registered and recovered cases after a sixty-day lockdown in Italy: A data-driven model approach. J Microbiol Immunol Infect 53: 396-403. [crossref]

19. Barkur G, Vibha Kamath GB (2020) "Sentiment analysis of nationwide lockdown due to COVID 19 outbreak: Evidence from India" (in eng). Asian J Psychiatry 51: 102089. [crossref]

20. Chatterjee K, Chatterjee K, Kumar A, Shankar S (2020) Healthcare impact of COVID-19 epidemic in India: A stochastic mathematical model. Med J Armed Forces India.

21. Zambrano-Monserrate MA, Ruano MA, Sanchez-Alcalde L (2020) Indirect effects of COVID-19 on the environment. Sci Total Environ 728: 138813. [crossref]

22. Cao W, et al. (2020) The psychological impact of the COVID-19 epidemic on college students in China. Psychiatry Res 287: 112934. [crossref]

23. Francis NN, Pegg S (2020) Socially distanced school-based nutrition program under COVID 19 in the rural Niger Delta. The Extractive Industries and Society.

24. Haleem A, Javaid M, Vaishya R (2020) Effects of COVID 19 pandemic in daily life, (in eng). Curr Med Res Pract.

25. Jin H, Lu L, Liu J, Cui M (2020) Complex emergencies of COVID-19: management and experience in Zhuhai, China. Int J Antimicrobial Agents 55: 105961. [crossref]

26. Lau H, et al. (2020) Internationally lost COVID-19 cases. J Microbiol Immunol Infect 53: 454-458. [crossref]
27. (2012) The American Journal of Emergency Medicine. Wilderness \& Environmental Medicine 23: 89 .

28. Roy D, Tripathy S, Kar SK, Sharma N, Verma SK, et al. (2020) Study of knowledge, attitude, anxiety \& perceived mental healthcare need in the Indian population during COVID-19 pandemic. Asian J Psychiatry.

29. Rajkumar RP (2020) COVID-19 and mental health: A review of the existing literature. Asian J Psychiatry 52: 102066. [crossref]

30. Zhang D, Hu M, Ji Q (2020) Financial markets under the global pandemic of COVID-19. Finance Res Lett 36: 101528. [crossref]

31. Gallego V, Nishiura H, Sah R, Rodriguez-Morales AJ (2020) The COVID-19 outbreak and implications for the Tokyo 2020 Summer Olympic Games (in eng). Travel Med Infect Dis 34: 101604. [crossref]

32. Holmes EA, O'Connor RC, Perry VH, Tracey I, Wessely S, et al. (2020) Multidisciplinary research priorities for the COVID-19 pandemic: A call for action for mental health science. Lancet Psychiatry 7: 547-560. [crossref]

33. AEMO. Australian energy market operator, quarterly energy dynamics Q1 2020, market insights and WA market operations. AEMO.

34. Ahmed MZ, Ahmed O, Aibao Z, Hanbin S, Siyu L, et al. (2020) Epidemic of COVID-19 in China and associated Psychological Problems. Asian J Psychiatry 51: 102092. [crossref]

35. Bates M (2020) Public transport authorities and COVID-19, impact and response to a pandemic. International Association of Public Transport Australia/New Zealand.

36. CNBC. "World Markets"

37. Kabir M, Afzal MS, Khan A, Ahmed H (2020) COVID-19 pandemic and economical cost; impact forcibly displaced people, (in eng). Travel Med Infect Dis.

38. Krotkov NA, et al. Atmos Chem Phys 16, 4605-4629 (2016

39. Martin RV, et al. J Geophys Res 108, 4537 (2003).

40. Schneider P, van der ARJJ (2012) Geophys Res 117: 16309.

41. UNESCO. COVID-19 educational disruption and response.

\section{Citation:}

